\title{
A non-invasive optical method for mapping temperature polarization in direct contact membrane distillation
}

\author{
S. Santoro ${ }^{1,2,3}$, I.M. Vidorreta ${ }^{2}$, V. Sebastian' ${ }^{2}$, A. Moro ${ }^{3}$, I. M. Coelhoso ${ }^{3}$, C. A. M. Portugal \\ ${ }^{3}$, J. C. Lima ${ }^{3}$, G. Desiderio ${ }^{4}$, G. Lombardo ${ }^{5}$, E. Drioli ${ }^{1}$, R. Mallada ${ }^{2}$, J. G. Crespo ${ }^{3}$, A. \\ Criscuoli ${ }^{1}$, A. Figoli ${ }^{1 *}$
}

*e-mail: $\underline{\text { a.figoli@itm.cnr.it }}$

1 Institute on Membrane Technology (ITM-CNR), via P. Bucci 17/C, 87036 Rende (CS) Italy.

${ }^{2}$ Institute of Nanoscience of Aragon (INA) and Department of Chemical, Engineering and Environmental Technology, University of Zaragoza, C/ Mariano Esquillor, s/n, $I+D+i$ Building, 50018, Zaragoza, Spain

${ }^{3}$ LAQV, REQUIMTE, Departamento de Química, Faculdade de Ciências e Tecnologia, Universidade Nova de Lisboa, 2829-516 Caparica, Portugal

${ }^{4}$ Istituto di Nanotecnologia (CNR - NANOTEC), Via P. Bucci 31c, 87036 Rende (Cs) Italy

${ }^{5}$ Istituto per i Processi Chimico-Fisici, CNR-IPCF, Viale F. Stagno D’Alcontres 37, 98158, Messina, Italy

\begin{abstract}
Membrane Distillation (MD) is a thermal membrane process allowing for a theoretical $100 \%$ rejection of non-volatile compounds (i.e. ions, macromolecules, colloids, cells), whereas vapour molecules permeate through a micro-porous hydrophobic membrane due to a difference of vapour pressure established across the membrane-self. The effective driving force and, then, the vapour trans-membrane flux is affected by temperature polarization phenomena occurring in the boundary layers adjacent to the membrane. The temperature values at the membrane surface are usually difficult to measure and only recently some invasive techniques were adopted for this scope.

The aim of this work was to introduce luminescent molecular probing as an innovative technology for non-invasive and in-situ monitoring of thermal polarization in MD. Tris(phenantroline)ruthenium(II) chloride $\left(\mathrm{Ru}(\mathrm{phen})_{3}\right)$ was selected as temperature sensitive luminescent probe and immobilized in a flat poly(vinylidene fluoride) electrospun nanofibrous membrane (PVDF ENM). Experiments showed the key role of the $\mathrm{Ru}(\mathrm{phen})_{3}$ and Lithium Chloride ( $\mathrm{LiCl})$ in the preparation of homogeneous PVDF ENM due to their
\end{abstract}


ionic nature that improved the electrical conductivity of the polymeric solution favouring the electrospinning. Furthermore, PVDF ENM showed a good performance in Direct Contact Membrane Distillation (DCMD) process. The immobilization of the molecular probe allowed to optically monitoring the membrane surface temperature during DCMD experiments. On the other hand, the employment of an IR-camera permitted the evaluation of the temperature of the bulk of liquid streams. Therefore, the combination of these two optical techniques enabled to evaluate, in a direct and non-invasive way, the thermal polarization along the membrane module during DCMD experiments.

\section{Graphical Abstract}

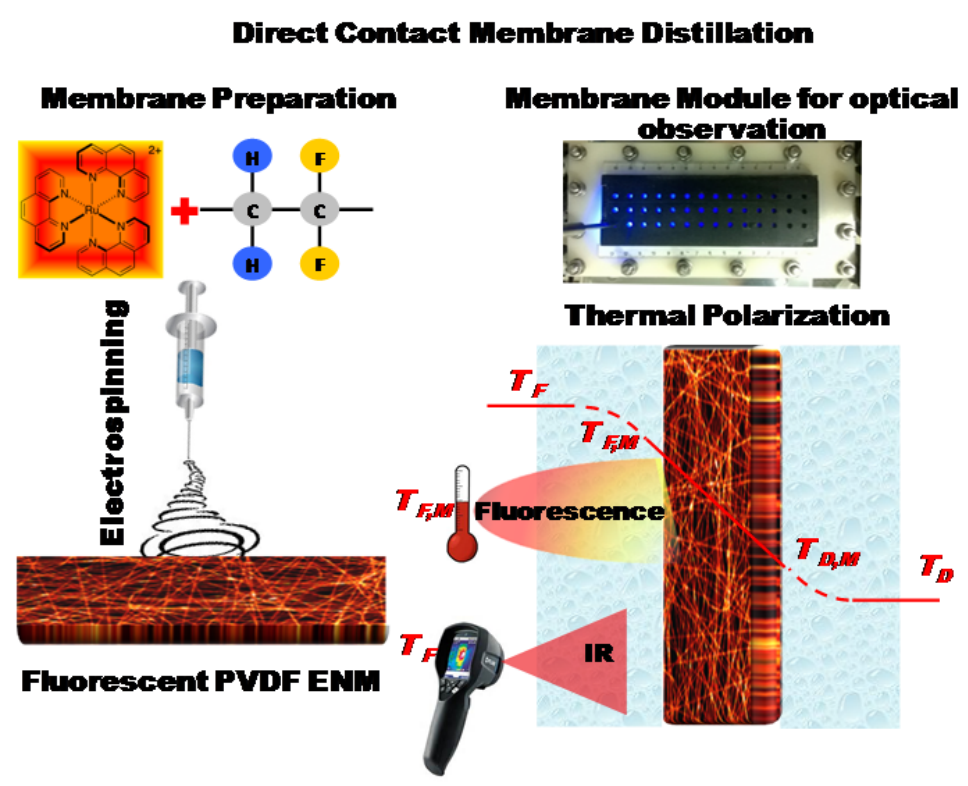

\section{Keywords:}

Luminescent Molecular Probes, Electrospinning, Nanofibrous Membrane, Direct Contact Membrane Distillation, Thermal Polarization.

\section{Highlights:}

PVDF Electrospun Nanofibrous Membranes doped with Ru(phen $)_{3}$ were prepared PVDF Electrospun Nanofibrous Membranes were tested in DCMD

The molecular probe $\mathrm{Ru}(\mathrm{phen})_{3}$ allowed to monitor the temperature on membrane surface An IR-camera allowed to monitor the temperature of the bulk of aqueous streams The thermal polarization coefficient was evaluated 


\section{Introduction}

Membrane distillation (MD) is a non-isothermal separation process allowing vapour molecules to permeate through a micro-porous hydrophobic membrane, whereas theoretical $100 \%$ rejection of ions, macromolecules, colloids, cells and other non-volatiles is obtained [1-3]. MD is considered a promising technology in a wide range of applications in water treatment such as desalination, removal of contaminants and organic matter, concentration of aqueous solutions [4]. In fact, MD is a non-intensive energetic separation process operating at lower pressure than conventional pressure-driven membrane separation processes and requiring lower heat with respect to conventional distillation, that could be provided by thermal renewable energy sources (i.e. solar) [5].

Nevertheless, several technological drawbacks have limited the implementation of MD at industrial scale and hindered commercial visibility, such as the development of membranes with adequate and devoted properties and the optimization of the module design and operating conditions in order to limit polarization phenomena occurring in the boundary layers adjacent to the membrane [6-7].

An ideal membrane for MD should present a superhydrophobic surface to avoid pore wetting and a well-designed pore structure to favour water vapour transport [8-9]. Poly(vinylidene fluoride) (PVDF) has gained great attention as a membrane material with regard to its outstanding properties such as high mechanical strength, thermal stability, chemical resistance, combined with solubility in a wide number of common solvents which allowed the preparation of membranes with designed morphology using different techniques [10]. Among them, electrospinning is a promising technique which enables to produce self-standing electrospun nanofibrous membranes (ENMs) characterized by interconnected open pore morphology made of a 3D network of hydrophobic nano-fibers, leading to high performance in terms of mass transport in MD process [11-16]. The most studied configuration in MD is the direct contact membrane distillation (DCMD) where the membrane is in between two aqueous streams at different temperatures producing a gradient of vapour pressure across the membrane that represents the driving force for the process. As shown in Figure 1, mass and heat transfers are correlated: heat is transferred from the feed to the permeate by the evaporation and the condensation of the permeating species and as conductive heat through the membrane matrix [17]. As a consequence of the thermal polarization in the boundary layer (Figure 1), the membrane temperature at the feed side $\left(\mathrm{T}_{\mathrm{F}, \mathrm{M}}\right)$ is lower than the value of 
bulk feed $\left(\mathrm{T}_{\mathrm{F}}\right)$ while the temperature of the membrane at the distillate side $\left(\mathrm{T}_{\mathrm{DM}}\right)$ is higher than the value of bulk distillate $\left(\mathrm{T}_{\mathrm{D}}\right)$. For this reason, the driving force dramatically decreases across the membrane negatively affecting the performance of MD processes [18].

Efforts have been devoted to the development of membrane modules in order to minimize this phenomenon by improving the fluid dynamics [19-20]. On the other hand, several mathematical models based on the heat and mass transfer equations have been developed to evaluate the thermal polarization [21-22]. Basically, studies have been focused on the analysis of effects of the thermal polarization by referring only to the overall performance in terms of heat or mass flux of the process, while minor attention was dedicated to the local characterization of the thermal polarization. In this respect, it is desirable to have a method able to monitor/evaluate in-situ the temperature in the membrane module and on the membrane surface without altering the operating conditions of the distillation process or the membrane properties. Recently, invasive techniques such as thermocouples located on the membrane surface [23] and spacer filled by thermochromic liquid crystals [24] have been proposed for the evaluation of the thermal polarization.

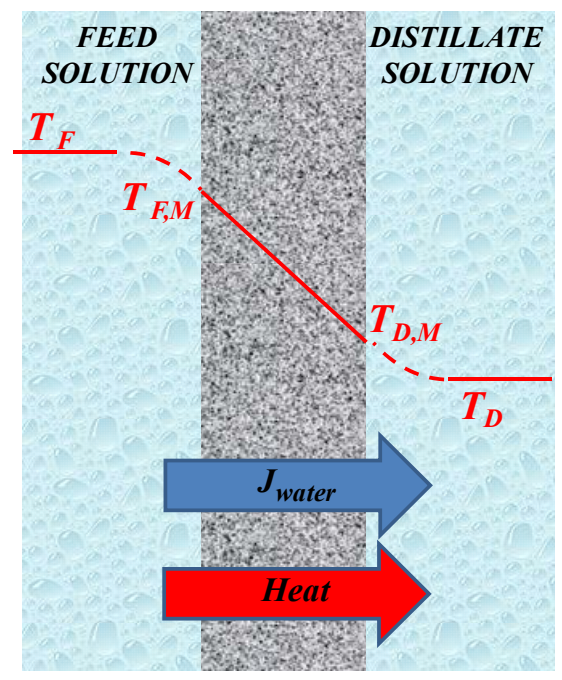

Figure 1: Thermal polarization.

The aim of this work was to propose luminescent molecular probes as an innovative technology for non-invasive and spatial monitoring of temperature in membrane processes. In fact, the employment of an optical sensor based on the dispersion luminescent molecules in 
polymeric matrix is an actual technology for the temperature sensing in several innovative fields of nano-science [25-26]. In our previous work, it was demonstrated that the immobilization of molecular probes in a dense membrane made of PS enables the noninvasive, on-line and in-situ monitoring of the temperature and oxygen concentration [27-29]. Nevertheless, this is the first time that the possibility of using an optical non-invasive method for in-situ determination of temperature polarization in membrane distillation was proved. Tris(phenantroline)ruthenium(II) chloride $\left(\mathrm{Ru}(\mathrm{phen})_{3}\right)$ was selected as temperature sensitive luminescent probe and immobilized in a PVDF ENM prepared via electrospinning on the basis of its photochemical and thermal stability and pronounced thermal sensitivity of the intensity of its emission [30-31]. Moreover, the thermal-driven non-radiative decay of the excited state of Ruthenium polypyridyl complexes leads to a thermal quenching which at low temperatures shows a linear decrease of the emission intensity with temperature [31]. The PVDF ENM was then tested in DCMD. The immobilization of the luminescent molecular probe and the design of a specific membrane module connected to a spectrofluorometer, by means of an optical fiber, allowed to monitor on-line the temperature of the membrane in both the feed and distillate sides $\left(\mathrm{T}_{\mathrm{F}, \mathrm{M}}, \mathrm{T}_{\mathrm{D}, \mathrm{M}}\right)$ during the DCMD process by measuring the phosphorescent activity of the luminescent molecular probe. On the other hand, the employment of an IR-camera allowed monitoring the temperature of the bulk of the streams of feed and distillate $\left(\mathrm{T}_{\mathrm{F}}, \mathrm{T}_{\mathrm{D}}\right)$. The combination of these two optical techniques is really promising since it enables the on-line and non-contact characterization of temperatures unrevealing the thermal polarization along the membrane module during DCMD experiments.

\section{Materials and methods}

\subsection{Materials}

The luminescent molecular probe tris(phenantroline)ruthenium(II) chloride $\left(\mathrm{Ru}(\mathrm{phen})_{3}\right)$ was purchased by Sigma-Aldrich, Spain. Poly(vinylidenefluoride) ((PVDF) Solef ${ }^{\circledR}$ 6012, Solvay Specialty Polymers, Bollate, Italy) was solubilised in a blend of solvents such as N,NDimethylformamide (DMF, 99.8\%, Sigma Aldrich, Spain) and acetone (Panreac, Spain). Lithium chloride (LiCl, Fisher Chemicals, Spain) was employed as additive.

\subsection{Membrane preparation}

PVDF solutions were prepared by adding the polymeric powder to $12 \mathrm{~mL}$ mixture of DMF/Acetone (6:4 wt:wt). The polymer concentration was varied from $6 w t \%$ to $10 w t \%$. 
Homogeneous solutions were obtained by stirring overnight at a temperature of $70^{\circ} \mathrm{C}$ the mixture of solvents and, then, adding PVDF. In the case of membranes doped with the molecular probe, $10 \mathrm{mg}$ of $\mathrm{Ru}(\mathrm{phen})_{3}(0.83 \mathrm{wt} \%$ with respect to the PVDF) and $5 \mathrm{mg}$ of $\mathrm{LiCl}$ $(0.43 \mathrm{wt} \%$ with respect to PVDF) were first solubilized in the mixture of DMF/Acetone (6:4 wt:wt) and then PVDF was added and stirred at $70^{\circ} \mathrm{C}$ until an homogeneous solution was reached. After cooling at room temperature, the solution was transferred in a syringe and connected to the electrospinning set-up. The solution properties were characterized using a Fungilab Visco Basic Plus Viscometer and a ABB X400 conductivimeter.

\subsection{Electrospinning}

Yflow 2.2 D500 electrospinner with a 20-gauge needle was used to obtain the fibers. The flow rate of the solution was adjusted to $1 \mathrm{~mL} \mathrm{~h}^{-1}$. The needle was placed $15 \mathrm{~cm}$ away from a flat collector. The optimum voltage was adjusted to $+16 \mathrm{KV}$ in the needle and $-2 \mathrm{KV}$ in the collector. In order to obtain homogeneous films, the needle was moved in 2 dimensions ( 80 $\mathrm{mm}$ left-right, $150 \mathrm{~mm}$ front-rear) to cover all the electrospinning area and obtain a homogeneous thickness of the membrane. After electrospinning the PVDF ENM was dried in oven at $100^{\circ} \mathrm{C}$ for 1 hour to remove traces of solvents and then overnight at $130^{\circ} \mathrm{C}$ between two flat glass panes to improve the cohesion between the nano-fibers (post-treatment). In fact, the thermal post-treatment of PVDF ENM is considered crucial to guarantee the integrity of PVDF ENMs preventing membrane pores from wetting in DCMD operation [16, 32-33].

\subsection{Membrane characterization}

The novel PVDF membranes prepared via electrospinning were characterized by several techniques:

Thickness- The thickness of membranes was evaluated by means of a digital micrometer Carl Mahr D 7300 (Esslingen AN, Gottingen, Germany) with an accuracy of $\pm 0.1 \mu \mathrm{m}$. For each membrane, ten measurements were taken.

Scanning Electron Microscopy (SEM) analysis- The morphology of membranes was observed by scanning electron microscope (SEM; Steroscan 360, Cambridge Instruments, Cambridge, UK).All samples were sputter-coated with gold immediately before observation.

Confocal Microscopy Imaging set-up- The set-up is based on an Leica SP8 confocal laser scanning microscope (Leica Microsystems GmbH, Germany) upright microscope configured 
to enable high sensitivity imaging. The system is equipped with an Argon laser $(65 \mathrm{~mW})$ and it was used the laser line wavelength of $458 \mathrm{~nm}$ to excite the membrane sample doped with $\mathrm{Ru}(\mathrm{phen}) 3$. The laser is coupled into the Leica SP8-Spectral Scan-Head where it passes through the $\mathrm{x}-\mathrm{y}$ scanning mechanism, allowing the scanning in the $\mathrm{x}-\mathrm{y}$ focal plane, before being focused by a Leica HCX IRAPO 25X/095 NA IRAPO water immersion objective with a working distance of $2.5 \mathrm{~mm}$. The system was set-up to acquire images with a frequency of $400 \mathrm{~Hz}$ and a pixel to voxel size ratio of $100 \mathrm{~nm}$. A Typical frame acquisition time varied from $1.5 \mathrm{sec}$ up to $100 \mathrm{sec}$ for acquiring 500x500 pixels up to 4096x4096 pixels respectively. A single image was then line and frame averaged 3 times to reduce noise. The light emitted from the doped sample was acquired in epi-detection by a photomultiplier tube (PMT) which was set-up to collect the light in the range 520 to $750 \mathrm{~nm}$ by the use of the filter-free spectral detecting system.

Contact angle $(\boldsymbol{C A})$ - The contact angles with distilled water on both the surfaces were measured using a CAM 200 contact angle meter (KSV Instruments, Finland) by the sessile drop method at ambient temperature. After taken 10 measurements, the average value and the corresponding standard deviation were calculated.

Porosity (P)- Membrane porosity was evaluated by the gravimetric method consisting in weighing the membrane in dry and wet conditions ( $24 \mathrm{hr}$ in kerosene). The overall porosity was calculated according to the following equation [34]:

$$
\mathrm{P}=\frac{\frac{w_{\mathrm{h}}-w_{\mathbf{d}}}{\rho_{\mathrm{w}}}}{\frac{\mathrm{w}_{\mathbf{d}}}{\rho_{\mathrm{PVDF}}}+\frac{w_{\mathrm{h}}-w_{\mathrm{d}}}{\rho_{\mathrm{w}}}} ;
$$

where $\mathrm{w}_{\mathrm{h}}$ is the weight of the wet membrane; $\mathrm{w}_{\mathrm{d}}$ is the weight of the dry membrane; $\rho_{\mathrm{w}}$ is the kerosene density $\left(0.82 \mathrm{~g} \mathrm{~cm}^{-3}\right)$ and $\rho_{\text {PVDF }}$ is the polymer density $\left(1.72 \mathrm{~g} \mathrm{~cm}^{-3}\right)$. For each membrane, three measurements were performed; the average value and the corresponding standard deviation were, then, calculated.

Pore size $\left(d_{p}\right)$ - Membrane bubble point and pore size were measured using a PMI Capillary Flow porometer (Porous Materials Inc., US). According to the procedure reported in literature [35], membranes were immersed for 24 hours in Porewick (16 dyne $\left.\mathrm{cm}^{-1}\right)$ and then tested in the membrane module of the porometer using wet-up/dry-up method programmed by the software Capwin. The method is based on the increasing of the pressure in a 
compartment of the membrane cell to remove the Porewick from the pores and, then, repeating the test using the dry sample. The data were processed using the software Caprep which correlates the applied pressure $\mathrm{P}$ to the pore size $\mathrm{d}_{\mathrm{P}}$ according to the Laplace equation:

$$
d_{p}=\frac{4 \tau \cos \theta}{P}
$$

where $\tau$ is the surface tension of the liquid, $\theta$ is the contact angle of the liquid (assumed to be 0 in case of full wetting, which means $\cos \theta=1$ ).

Liquid Entry Pressure (LEP)- The liquid entry pressures (LEPs) of the membranes were measured by means of a static liquid chamber filled-up with $200 \mathrm{~mL}$ of DI water at ambient temperature accommodating the membrane sample $\left(\right.$ area $4 \mathrm{~cm}^{2}$ ). The pressure in the chamber was increased at a constant rate of 0.1 bar per $10 \mathrm{~min}$ until the water permeated trough the membrane. Experiment was repeated twice with different membrane samples at the same conditions and the average value evaluated was the LEP.

\subsection{Monitoring of temperature on membrane surface during direct contact membrane distillation (DCMD) experiments}

DCMD experiments were performed using the set-up presented in Figure 2. The distillate stream was kept at an inlet temperature of ca. $18-19^{\circ} \mathrm{C}$, whereas the feed was heated-up to 40 , 50 and $60^{\circ} \mathrm{C}$ by a heater (Thermo Haake ${ }^{\circledR}$ heating circulator C10). Thermocouples (HD9214, Delta OHM, accuracy $\pm 0.1^{\circ} \mathrm{C}$ ) placed in proximity of the inlets and outlets of the membrane module were employed to monitor the temperature of the two pure water streams that were fed at a co-current flow rate of $12 \mathrm{~L} \mathrm{~h}^{-1}$ by means of two peristaltic pumps (Masterflex ${ }^{\circledR}$ 7518-10). An analytical balance (Europe 6000, Gibertini) was used for weighing the distillate. 

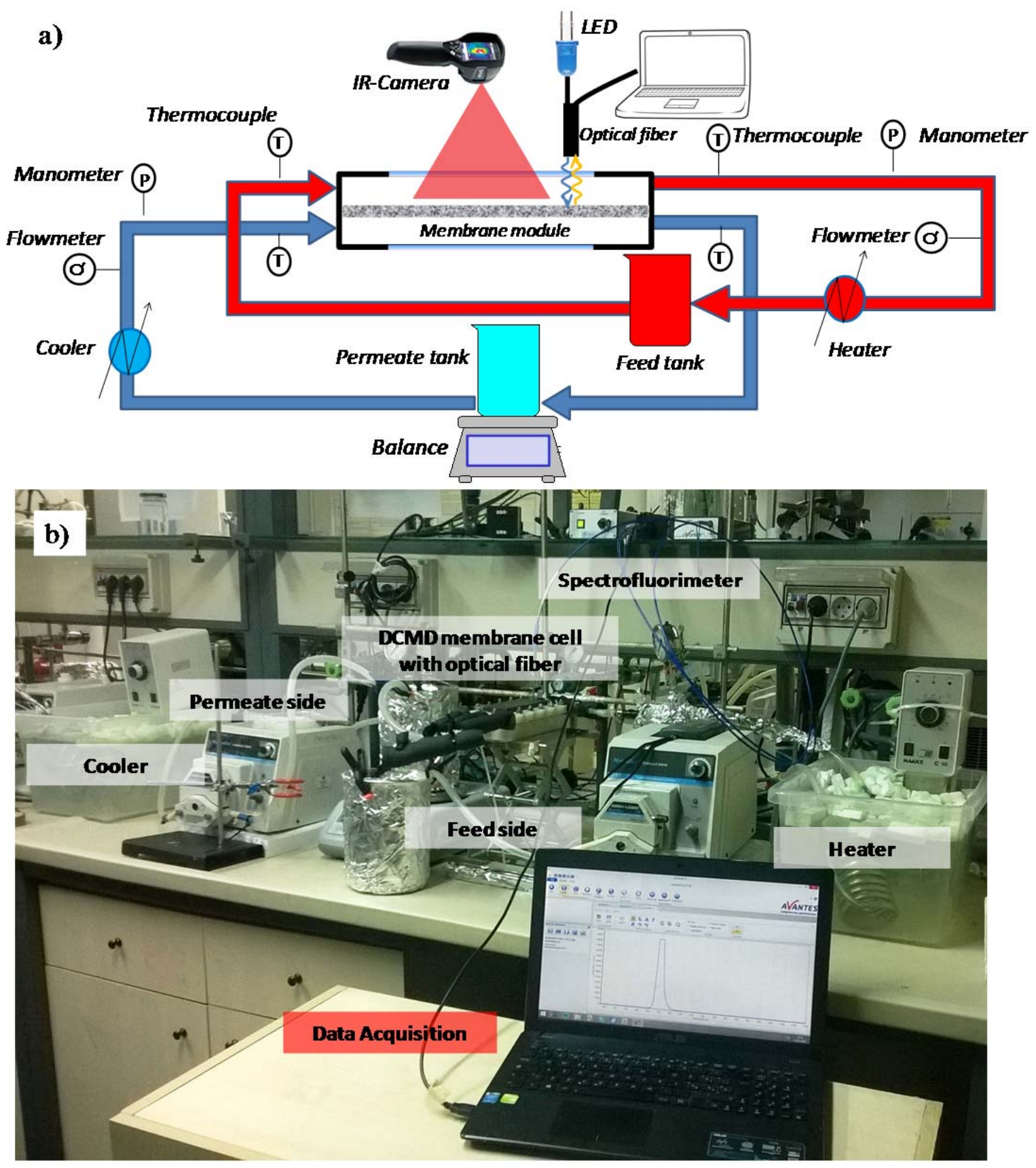

Figure 2: a) Scheme of the set-up used for monitoring the temperature in DCMD process, b) Picture of the set-up.

The membrane module made of Nylon (Figure 3) in which the membrane sample (size: 16 $\mathrm{cm} \times 5.5 \mathrm{~cm}$, active area: $88 \mathrm{~cm}^{2}$ ) was placed had a polymeric window transparent in the near-UV/visible region which allowed to excite the luminescent molecular probes 
immobilized into the membrane and to collect their emission by means of a bifurcated fiberoptical bundle UV/Visible (Ocean Optics) connected to a spectrofluorimeter (Avantes). The excitation wavelength was fixed at $450 \mathrm{~nm}$, a value closed to the maximum peak of absorbance of the $\mathrm{Ru}(\mathrm{phen})_{3}(489 \mathrm{~nm})$. The acquisition time of spectra was set at $0.2 \mathrm{~s}$ and 10 spectra were averaged for each measurement in order to obtain the maximum signal to noise ratio.

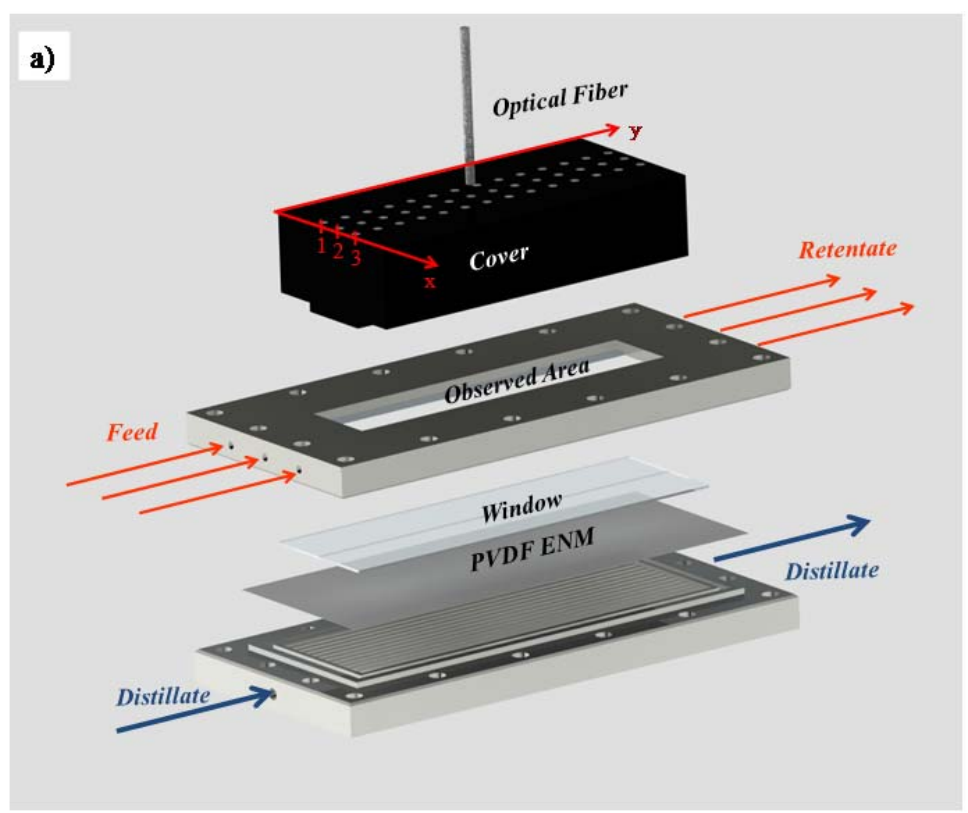

b)

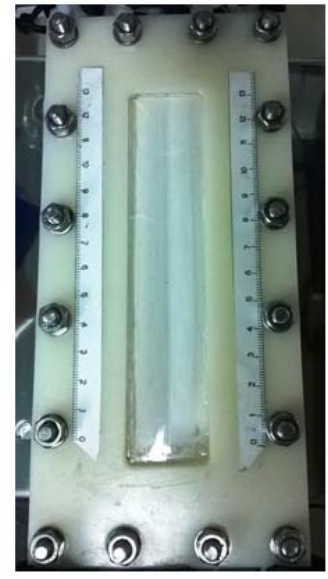

c)

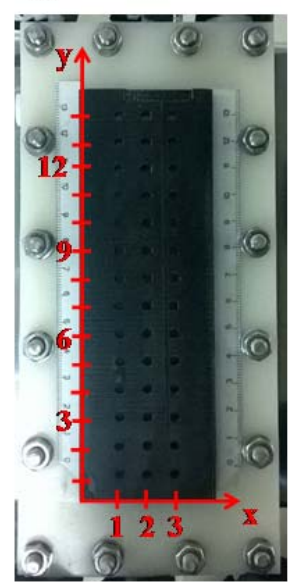

d)

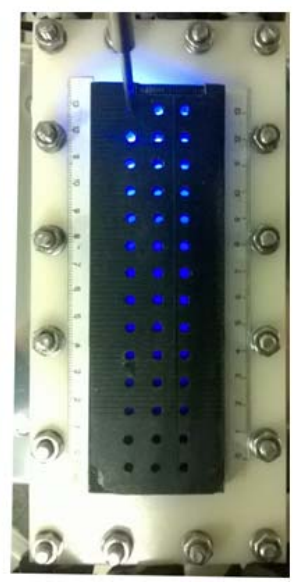

Figure 3: Scheme of the developed membrane module for optical observations (a); Pictures evidencing the window (b), the cover (c) and the optical-fiber (d).

A membrane module cover with 42 holes displaced in 3 rows $\left(x_{1}=1.7 \mathrm{~cm} \mathrm{(1),} x_{2}=2.7 \mathrm{~cm} \mathrm{(2),}\right.$ $\mathrm{x}_{3}=3.7 \mathrm{~cm}$ (3)) allowed to fix the optical fiber at $90^{\circ}$ with respect to the sample surface, to excite the membrane and to detect the emitted phosphorescence from each hole. 
Before each session of measurements, the spectrophotometer setup was calibrated by acquiring a dark signal. The dark signal was obtained by turning off the LED. Then the emission spectrum acquired for each hole was therefore normalized with respect to the dark signal. A calibration procedure was performed in order to correlate the acquired phosphorescence signals in each hole to the temperature. The calibration curves were obtained by plotting the amplitude of the emitted phosphorescence at $572 \mathrm{~nm}$ as a function of the water temperature. In particular, during the calibration procedure, the two water streams (feed and distillate) were kept at the same temperature $\left(40,50\right.$ and $\left.60^{\circ} \mathrm{C}\right)$, in order to avoid simultaneous heat and mass transfer across the membrane. The thermocouples placed in the proximity of the membrane module were used to check the temperature change along the membrane module. For each experimental measurement the slope of the linear regression of the phosphorescence amplitude vs temperature $\left(\mathrm{R}^{2}>0.96\right)$ was extracted.

During DCMD experiments, a cold stream at $15^{\circ} \mathrm{C}$ was fed to one compartment of the membrane module and, after $60 \mathrm{~min}$, necessary to achieve the steady state, the flux was registered for 4 hours. In each hole, the phosphorescence was also measured during the DCMD process and the temperature of the membrane surface was evaluated in real-time using the calibration curves.

A two-dimensional mapping of the temperature on the membrane surface was derived by linear interpolation of the temperature values in each hole. For this purpose, a numerical processing was performed by writing a custom Matlab routine (Matlab, The MathWorks Inc., Natick, MA, USA) using the gridded interpolant function.

The temperature of bulk of the streams was evaluated by means of an IR CAMERA (model FLIR E40) with a thermal sensitivity of $0.07^{\circ} \mathrm{C}$ at $30^{\circ} \mathrm{C}$. Infra-red pictures of a resolution of $160 \times 120$ pixels were acquired in the spectral range from $7.5 \mu \mathrm{m}$ to $13 \mu \mathrm{m}$ and were collected by placing the IR CAMERA at a distance of ca. $50 \mathrm{~cm}$ from the membrane module.

\section{Results and Discussion}

\subsection{Membrane composition and morphology}

PVDF ENMs were electrospun starting from a polymeric solution prepared using a mixture of DMF/Acetone. Basically, DMF is used as good solvent for PVDF whereas acetone has the key role to accelerate solvent evaporation due to its superior vapour pressure facilitating the formation of the 3D network [36]. 
a)

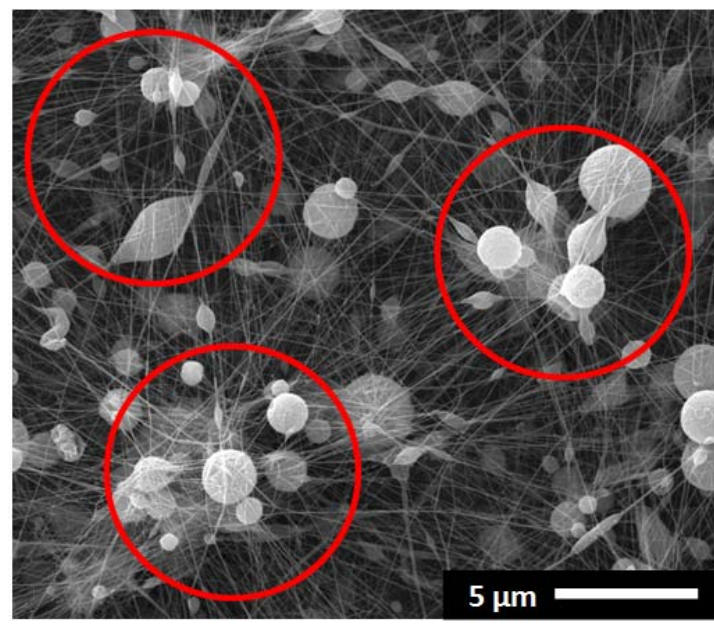

c) $10 w t \%$ PVDF/Ru(phen) 3

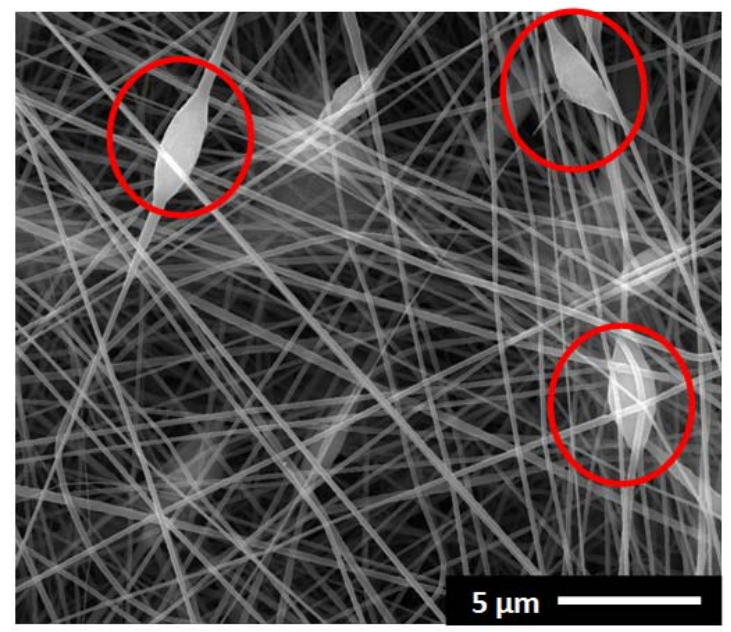

b) $\quad 10 w t \%$ PVDF

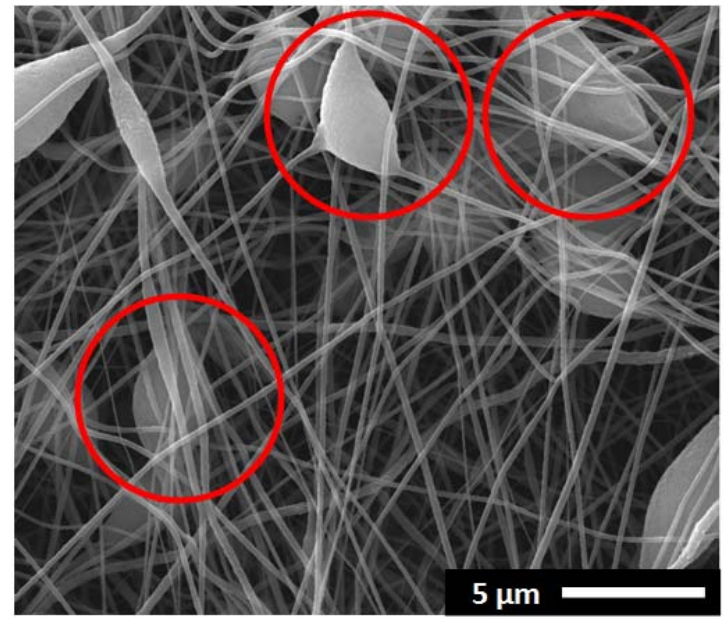

d)10 wt \% PVDF/Ru(phen) $3 /$ LiCl

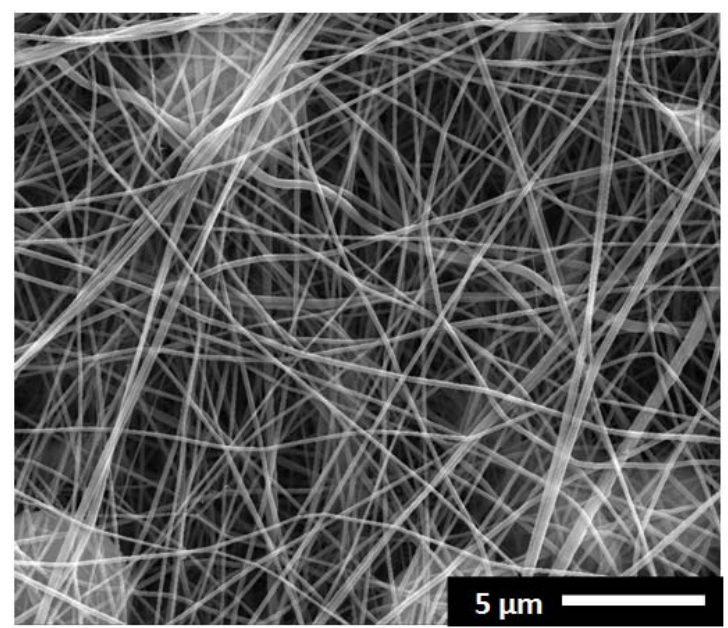

Figure 4: SEM picture of PVDF ENMs (Magnification: 10,000 X, scale bar 5 microns): a) PVDF 6wt\%, b) PVDF 10wt\%, c) PVDF 10wt\%+0.85wt\% Ru(phen) $)_{3}$ d) PVDF $10 w t \%+0.85 w t \% R u(\text { phen })_{3}+0.43 w t \% ~ L i C l$.

The optimal concentration to electrospin the nano-fibers was found to be $10 \mathrm{wt} \%$ (Figure $4 \mathrm{~b}$ ). In fact, for higher concentration the viscosity of the polymeric solution was too high to be electrospun, whereas at lower concentration (i.e. $6 \mathrm{wt} \%$ ) the nano-fibers presented defects. 
a)

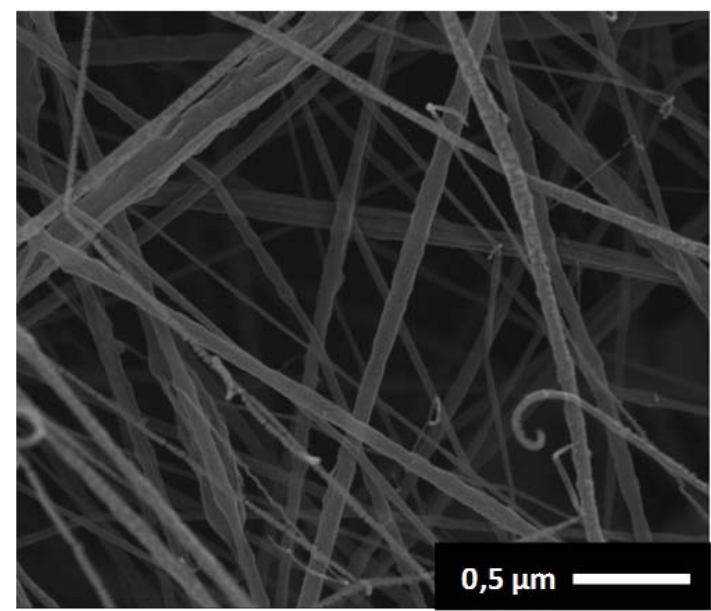

c) $10 \mathrm{wt} \%$ PVDF/R(phen) 3

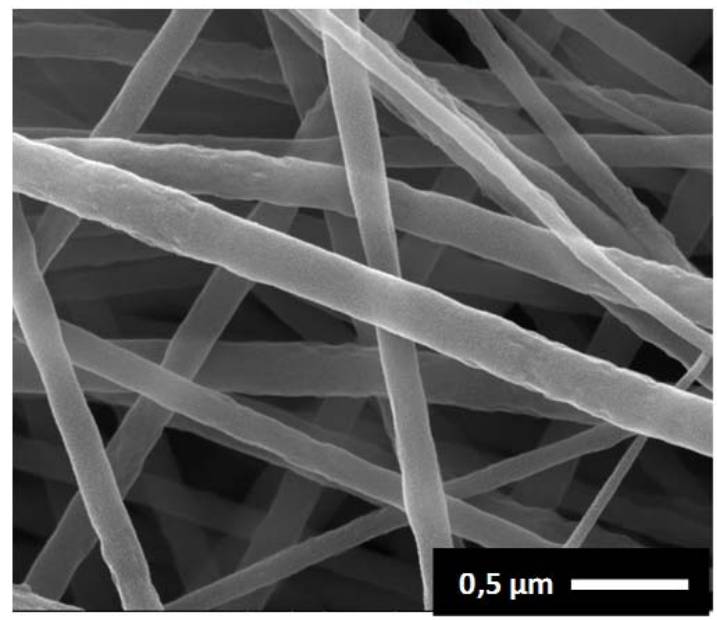

b) $10 w t \%$ PVDF

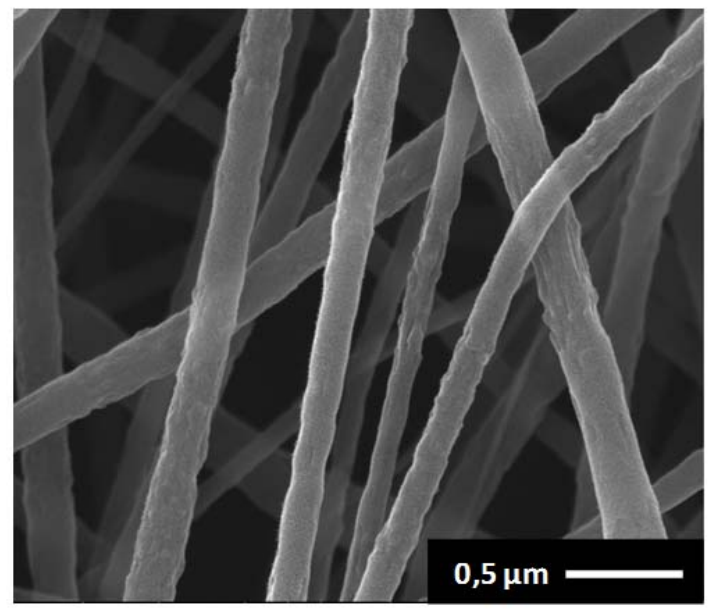

d)10 wt\% PVDF/Ru(phen) $)_{3} /$ LiCl

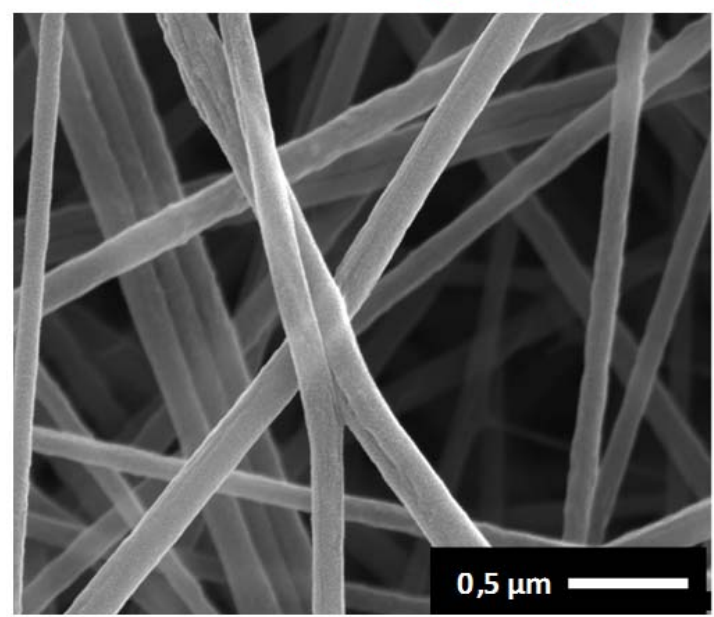

Figure 5: SEM picture of PVDF ENMs (Magnification: 100,000 X): a) PVDF 6wt\%, b) PVDF 10wt\%, c) PVDF $10 w t \%+0.85 w t \%$ Ru(phen $)_{3}$, d) PVDF $10 w t \%+0.85 w t \%$ Ru(phen $)_{3}+0.43 w t \% ~ L i C l$.

This is due to the fact that at low viscosities $(24.3 \mathrm{cP})$ the surface tension becomes the dominant factor during the electrospinning process and drops are formed instead of nanofibers as it is visible in the Figure 4.a [37]. By looking at Figure 5, it is possible to notice that the increase of the concentration of PVDF to $10 \mathrm{wt} \%$ dramatically improves the quality of the fibers as a consequence of the increasing of the viscosity of the polymeric solution to a value of $94.6 \mathrm{cP}$. However, ENM prepared with $10 \mathrm{wt} \%$ of PVDF some presented defects too (Figure 4.b.). 
The addition of $\mathrm{Ru}(\mathrm{phen})_{3}$ decreased the number and the size of drops (Figure 4.c), that disappeared by the addition of $\mathrm{LiCl}$. This is explained by the nature of the molecular probe and the additive. Both are salts which affect the electrical conductivity of the polymeric solution. In fact the electrical conductivity of the polymeric solution containing $10 \mathrm{wt} \%$ of PVDF in DMF/Acetone (6:4 wt:wt) was really low $\left(0.8 \mu \mathrm{S} \mathrm{cm}^{-1}\right)$, whilst raised to $76.3 \mu \mathrm{S} \mathrm{cm}^{-}$ ${ }^{1}$ by the addition of the molecular probes and up to $375 \mu \mathrm{S} \mathrm{cm}^{-1}$ by the employment of $\mathrm{LiCl}$ as additive. PVDF polymeric solution prepared with both $\mathrm{Ru}(\mathrm{phen})_{3}$ and $\mathrm{LiCl}$ presented an electrical conductivity of $394 \mu \mathrm{S} \mathrm{cm}^{-1}$. The use of salts, in particular $\mathrm{LiCl}$, is quite common in electrospinning membrane preparation in order to improve the conductivity of polymeric solution generating a higher charge density on the surface of the charged jet, thus favouring the formation of nano-fibers [36-38].

Table 1: Electrical conductivity (s) and viscosity (v) of PVDF polymeric solutions.

\begin{tabular}{|c|c|c|c|c|c|}
\hline Polymeric Solution & $\begin{array}{c}P V D F \\
{[w t \%]}\end{array}$ & $\begin{array}{c}\text { Ru(phen })_{3} \\
{\left[w t^{*}\right]^{*}}\end{array}$ & $\begin{array}{c}\mathrm{LiCl} \\
{[w t \%]^{*}}\end{array}$ & $\begin{array}{c}S \\
{\left[\mu S \mathrm{~cm}^{-1}\right]}\end{array}$ & $\begin{array}{c}v \\
{[c P]}\end{array}$ \\
\hline 6\% PVDF & 6 & & & $1.4 \pm 0.1$ & $24.3 \pm 0.1$ \\
\hline $10 \% P V D F$ & 10 & & & $0.8 \pm 0.1$ & $94.6 \pm 0.5$ \\
\hline $10 \% \mathrm{PVDF} / \mathrm{LiCl}$ & 10 & & 0.83 & $375.0 \pm 2.6$ & $107.2 \pm 0.4$ \\
\hline $10 \% \mathrm{PVDF} / \mathrm{Ru}(\mathrm{phen})_{3}$ & 10 & 0.43 & & $76.3 \pm 0.2$ & $98.3 \pm 0.6$ \\
\hline 10\% PVDF/LiCV/Ru(phen) ${ }_{3}$ & 10 & 0.43 & 0.83 & $394.0 \pm 6.1$ & $108.1 \pm 0.7$ \\
\hline
\end{tabular}

*wt\% with respect to $P V D F$

In fact, $10 \mathrm{wt} \% \mathrm{PVDF} / \mathrm{Ru}(\text { phen) })_{3} / \mathrm{LiCl}$ ENM (Figures 4.d, 5.d) showed a homogeneous 3D network defect free of nanofibers with a diameter of $145 \pm 12 \mathrm{~nm}$.

Accordingly, PVDF ENMs prepared by solubilising $10 \mathrm{wt} \%$ of polymer in the blend of the solvents doped with $\mathrm{Ru}(\text { phen })_{3}$ and $\mathrm{LiCl}$ were selected for DCMD experiments.

\subsection{Membrane Characterization}

The properties of the developed pure PVDF ENMs were compared to those of PVDF ENMS doped with $\mathrm{Ru}(\text { phen })_{3}$ (see Table 2). 
Table 2 : Characterization results of $10 w t \% P V D F / R u(p h e n)_{3} / \mathrm{LiCl}$ ENM compared with $10 w t \% P V D F / L i C l$ ENM.

\begin{tabular}{|c|c|c|}
\hline & $10 w t \% P V D F / R u(p h e n)_{3} / \mathrm{LiCl}$ & $10 w t \% P V D F / L i C l$ \\
\hline Thickness [ $\mu \mathrm{m}]$ & $48 \pm 1$ & $32 \pm 6$ \\
\hline CA $\left[{ }^{\circ}\right]$ & $115 \pm 4$ & $117 \pm 6$ \\
\hline $\mathbf{P}[\%]$ & $89 \pm 1$ & $90 \pm 1$ \\
\hline LEP [bar] & $1.0 \pm 0.1$ & $1.0 \pm 0.1$ \\
\hline$d_{p}[\mu m]$ & $0.75 \pm 0.04$ & $0.71 \pm 0.06$ \\
\hline
\end{tabular}

In both the cases, PVDF ENMs are really thin (up to about 50 micron), providing low resistance to the mass transport. Moreover the membranes showed a hydrophobic character with a contact angle of $115^{\circ}$. Hydrophobicity, that is a function of the chemical texture of the surface as well as its roughness [39], is crucial for MD processes for avoiding the permeation of liquid water through the membrane and for ensuring good rejection values. Electrospinning is a competitive fabrication technique for developing hydrophobic membranes due to the greater surface roughness that can be achieved. In fact, the PVDF ENMs prepared by electrospinning showed a higher hydrophobic character than the PVDF membranes obtained by phase inversion, that typically have a contact angle of $80^{\circ}$ [40]. Furthermore, the electrospinning allows an easy production of membranes with uniform pore size distribution, interconnected void space and significantly high porosity [10]. Table 3 shows some properties of PVDF ENMs reported in literature evidencing that the porosity is in any case higher than $80 \%$. Specially, the produced PVDF ENMs presented a porosity of $89 \%$ and narrow pore size distribution with an average pore diameter of $0.75 \mu \mathrm{m}$. Despite the high poresity and pore size, PVDF ENMs showed a LEP of ca 1 bar, due to their high hydrophobicity, that makes them suitable for DCMD. Moreover, it was possible to notice that the immobilization of the molecular probe did not affect the properties of the PVDF ENMs.

\subsection{DCMD results}

Figure 6.a shows the DCMD permeate fluxes multiplied by the thickness of the membranes as a function of three different feed temperatures. The water permeate flux increased with the feed temperature as expected. In fact, the flux raises from $9 \mathrm{~kg} \mathrm{~m}^{-2} \mathrm{~h}^{-1}$ to $15.7 \mathrm{~kg} \mathrm{~m}^{-2} \mathrm{~h}^{-1}$ increasing the temperature of the feed stream from $40^{\circ} \mathrm{C}$ to $60^{\circ} \mathrm{C}$, respectively. 
The high fluxes of the novel PVDF membrane are related to the low thickness and high porosity [41]. The thickness of the PVDF ENM lies between 30 and $50 \mu \mathrm{m}$, considered the optimal range for DCMD, providing enough heat transfer resistance to establish a water vapour pressure difference across the membrane, together with a reduced membrane resistance for the vapour transport [40-41]. Moreover, the high porosity of the PVDF ENM also offers a lower resistance to the mass transport and minimizes the heat loss by conduction since the thermal conductivity of air is an order of magnitude lower than that of the polymeric membrane material [6].

Finally, the $10 \mathrm{wt} \% \mathrm{PVDF} / \mathrm{Ru}(\mathrm{phen})_{3} / \mathrm{LiCl}$ showed stable performance for 4 hours for each temperature, with a quite low experimental error $(<2 \%)$ and no wetting was observed during the DCMD operating period (Figure 6.b).

Experiments show the outstanding performance of the PVDF ENMs in DCMD. In fact, ENMs generally present superior flux with respect to conventional flat-sheet membrane due to their excellent properties in terms of porosity, thickness and hydrophobicity. For example, PVDF Durapore commercial membranes made by Millipore and tested in DCMD at a feed temperature of $60^{\circ} \mathrm{C}$ presented a flux of $10.67 \mathrm{~kg} \mathrm{~m}^{-2} \mathrm{~h}^{-1}$ [47]. Moreover, the immobilization of $\mathrm{Ru}(\text { phen })_{3}$ did not alter the permeance of the ENM (Figure 6.a).

a)

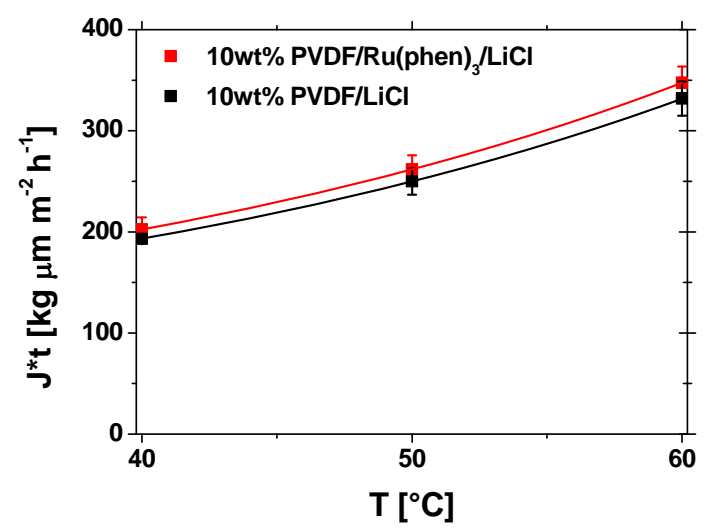

b)

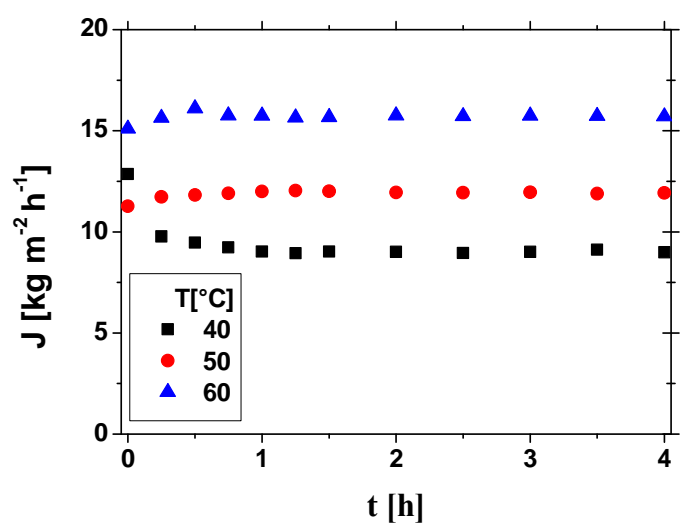

Figure 6: Comparison of the normalized flux mean values of bare PVDF ENMs and of PVDF ENMs doped with Ru(phen) ${ }_{3}$ (a) and flux of 10wt\%PVDF/ Ru(phen) ${ }_{3} / \mathrm{LiCl}$ as function of time and feed temperature (b) . 
From Table 3, it is possible to notice that the PVDF ENM developed presents competitive performance with literature data. In fact, PVDF ENM doped with $\mathrm{Ru}(\mathrm{phen})_{3}$ and prepared using $\mathrm{LiCl}$ as additive shows similar flux with respect to PVDF ENMs reported in the literature [44-46]. However, several studies showed that the performance of PVDF ENMs is further improved by inorganic fillers, such as silica nanoparticles and carbon nanotubes that can enhance the mechanical strength, thermal stability of the membrane and hydrophobicity [47-49].

Table 3. DCMD performance of the present study in comparison with ENMs reported in literature (Feed inlet temperature: $60^{\circ} \mathrm{C}$ ).

\begin{tabular}{|c|c|c|c|c|c|}
\hline Material & $d_{p}[\mu m]$ & $\mathbf{P}[\%]$ & CA $\left[^{\circ}\right]$ & $J\left[\mathrm{~kg} \mathrm{~m}^{-2} \mathrm{~h}^{-1}\right]$ & Reference \\
\hline PVDF Kynar 761 & $0.05-0.63$ & - & $87-151$ & $3-10^{*}$ & [44] \\
\hline PVDF Kynar 761 & $0.58-0.64$ & $81-82$ & $128-154$ & $<5 * *$ & [45] \\
\hline$P V D F$ & $2.9-5.2$ & $85-93$ & $137-141$ & $7.2-28.8 * *$ & [46] \\
\hline $\mathrm{PVDF}+\mathrm{SiO}_{2}$ & 0.69 & 82 & 156 & 18.9 & [47] \\
\hline Silica-PVDF/PVDF & $0.32-0.36$ & 80 & $150-154$ & $21 *$ & [48] \\
\hline$C N T / P V D F-c o-H F P$ & 0.29 & $>84$ & 158 & $29.5^{*}$ & [49] \\
\hline 10wt\%PVDF/ Ru(phen) $)_{3} / \mathrm{LiCl}$ & 0.75 & 89 & 115 & 15.7 & This Study \\
\hline
\end{tabular}

$* 35 \mathrm{~g} \mathrm{~L}^{-1} \mathrm{NaCl}$ feed

$* * 30 \mathrm{~g} \mathrm{~L}^{-1} \mathrm{NaCl}$ feed

\subsection{Evaluation of thermal polarization coefficient}

The temperature on the membrane surface was evaluated on the basis of the pronounced thermal quenching of the emission of $\mathrm{Ru}(\text { phen })_{3}$ immobilized in the PVDF membrane. Due to the microporous nature of PVDF ENM that induces scattering, diffusively reflection and absorption of the exciting light, the emission rise is attributed to the interface of the membrane (i.e. membrane surface).

In Figure 7, it is reported the emission collected from $10 \mathrm{wt} \% \mathrm{PVDF} / \mathrm{Ru}(\mathrm{phen})_{3} / \mathrm{LiCl}$ and the corresponding calibration curve of the membrane temperature as function of the emitted luminescence recorded at the hole $\mathrm{x}=2, \mathrm{y}=3$ (Figure 3). Doped PVDF ENM presents an unmatched emission attributed to the complex of $\mathrm{Ru}$ with a maximum emission at $572 \mathrm{~nm}$, 
blue shifted with respect to the emission observed by dispersing $\mathrm{Ru}(\mathrm{phen})_{3}$ in Polystyrene $(589 \mathrm{~nm})$ probably due to large change in polarity and polarizability of the fluorophore environment and the presence of aggregates [49]. Moreover, the difference in terms of the intensity of emission on membrane area at a fixed temperature is below 5\% indicating an homogeneous distribution of $\mathrm{Ru}(\mathrm{phen})_{3}$ in the membrane matrix. This is confirmed by the image of the PVDF ENM collected with the Confocal Microscope (Figure 8) evidencing the emission rising from $\mathrm{Ru}(\text { phen })_{3}$ homogenously immobilized in the nano-fibers.

The amplitude of the phosphorescence peak linearly decreased as the temperature increases. This effect is well known in photochemistry: the increasing of the temperature favours the non-radiative deactivation pathways of the molecular probe converting the absorbed light to the vibrational energy leading to the commonly observed decrease in phosphorescence intensity with rising temperature [39].

a)

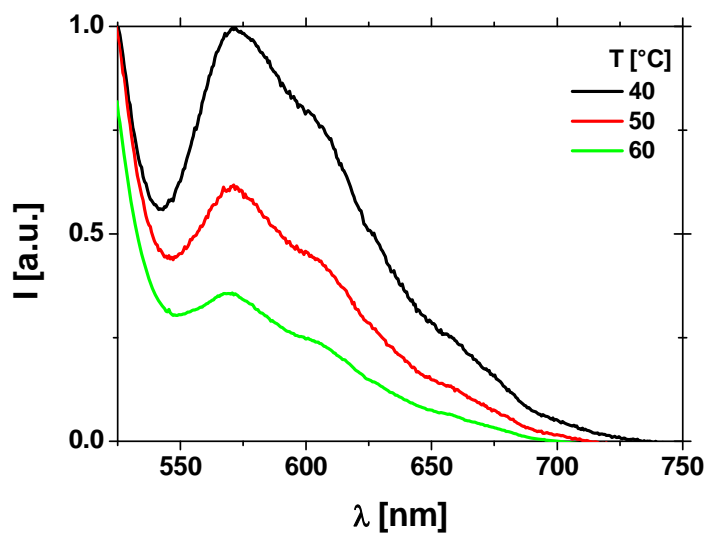

b)

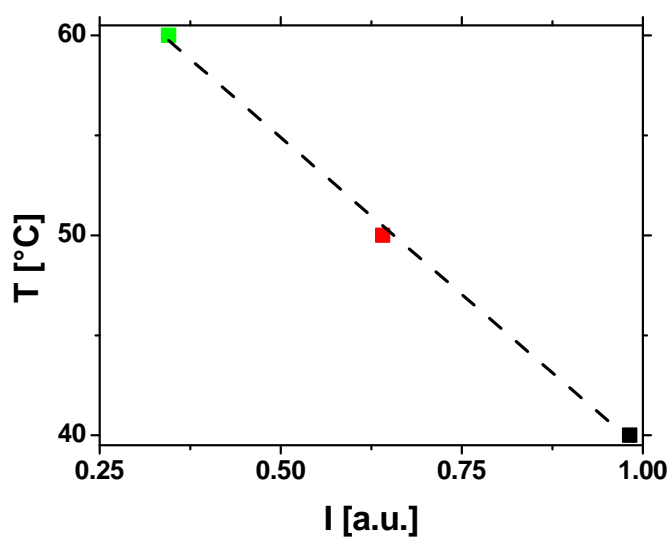

Figure 7: Emission spectra of Ru(phen) ${ }_{3}$ immobilized in PVDF ENM normalized with respect the value of the maximum of the emission $(572 \mathrm{~nm})$ collected at $40^{\circ} \mathrm{C}(\mathrm{a})$, and temperature sensitivity of the maximum of the emission (572 $\mathrm{nm}$ ) (b).

As a case study, the temperature of membrane surfaces (both in distillate and feed compartments) was derived from the calibration curve by measuring the emitted luminescence during DCMD carried out with a feed temperature of $60^{\circ} \mathrm{C}$ (Figure 8). The temperature of the feed of $60^{\circ} \mathrm{C}$ was chosen because of the higher heat and mass flux and, then, the higher polarization achievable. 


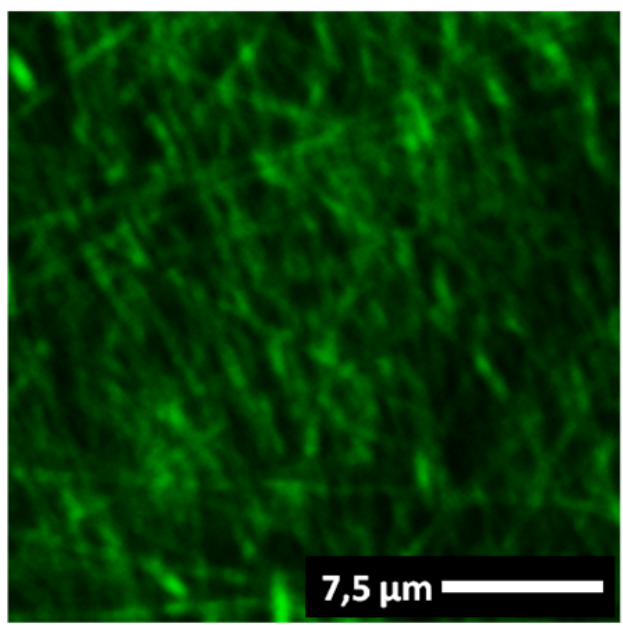

Figure 8: Confocal Microscopy Image of 10wt\%PVDF/ Ru(phen)3/LiCl ENM

The bi-dimensional maps of the membrane temperature at the feed $\left(\mathrm{T}_{\mathrm{F}, \mathrm{M}}\right)$ and distillate $\left(\mathrm{T}_{\mathrm{D}, \mathrm{M}}\right)$ sides are presented in Figures 8. In fact, because of the heat transfer, the temperature of the membrane surface decreases along the membrane module in the feed compartment, resulting that the temperature of the membrane surface in proximity of the outlet of the membrane module is much lower with respect to the temperature of the feed at the inlet. In fact, in proximity of the outlet of the membrane module the $\mathrm{T}_{\mathrm{F}, \mathrm{M}}$ is ca. $20^{\circ} \mathrm{C}$ lower with respect to $60^{\circ} \mathrm{C}$ of the feed solution $\left(\mathrm{T}_{\mathrm{F}, \mathrm{M}}=40.6 \pm 0.4^{\circ} \mathrm{C}\right.$ at $\mathrm{T}_{\text {feed }}=60^{\circ} \mathrm{C}$ and $\left.\mathrm{y}=14\right)$ 
a)

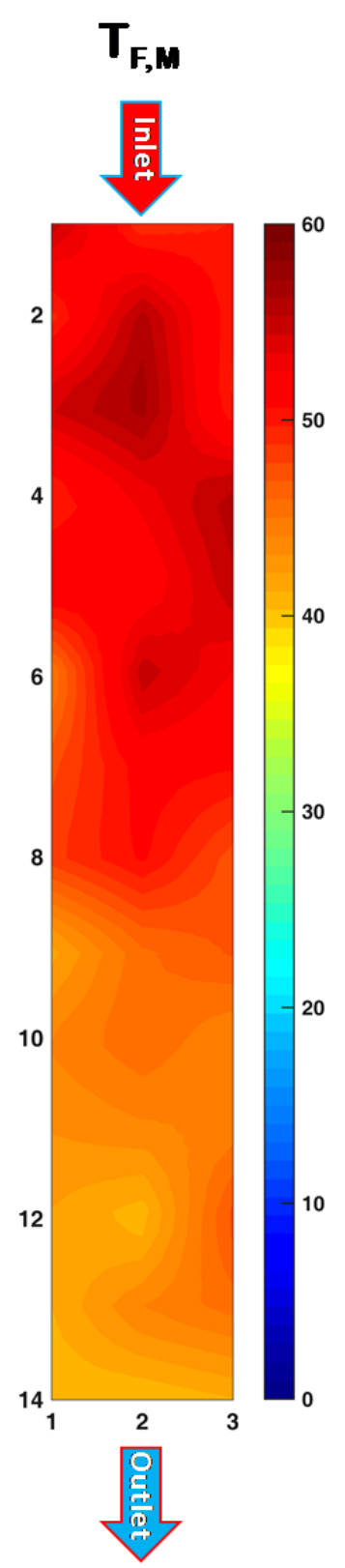

b) $\mathbf{T}_{\mathbf{D}, \mathbf{M}}$

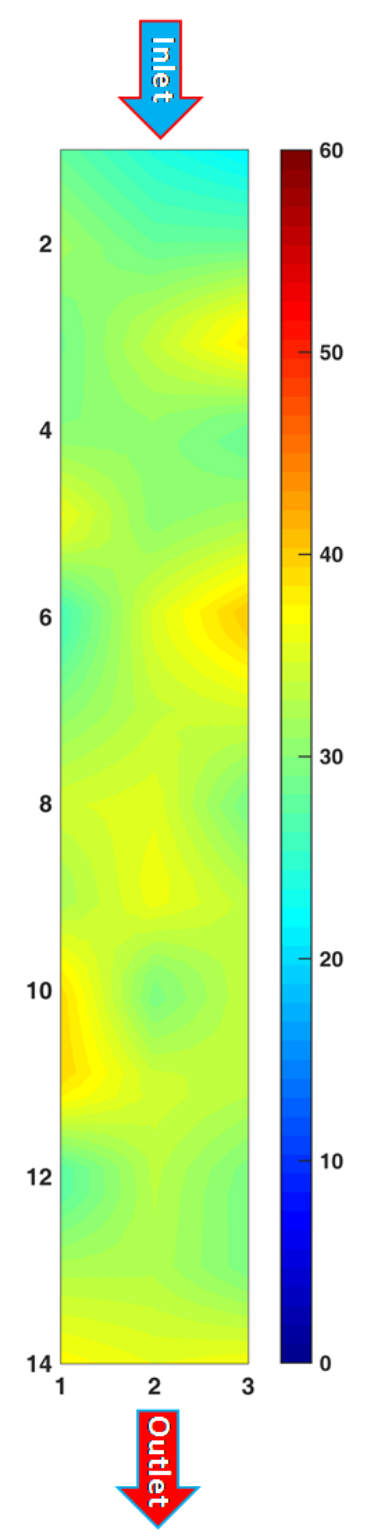

Figure 8: Topographic Maps of the temperature on membrane surface of PVDF ENM in a) the feed $\left(T_{F, M}\right)$ and $b$ ) distillate $\left(T_{D, M}\right)$ compartments using discrete optical fiber measurements together with gridded interpolant function, Matlab, at a temperature of the feed of $60^{\circ} \mathrm{C}$.

On the other hand, an opposite trend was observed in the case of the $\mathrm{T}_{\mathrm{D}, \mathrm{M}}$ as expected. In fact, recycling the distillate at ca $18-19^{\circ} \mathrm{C}$, the temperature on the membrane surface in the distillate compartment $\left(\mathrm{T}_{\mathrm{D}, \mathrm{M}}\right)$ is higher (around $23^{\circ} \mathrm{C}$ in proximity of the entry of the module) and the membrane temperature tends to increase along the membrane module. In particular, 
in proximity of the outlet of the membrane module $(\mathrm{y}=14)$ the $\mathrm{T}_{\mathrm{D}, \mathrm{M}}$ reaches a value of $36.4 \pm 0.4^{\circ} \mathrm{C}$. This is due to the heat transport related to the conduction across the membrane material together with a transport due to vapour flowing through the membrane.

Besides the temperature profile on the membrane surface, a minimal decay and increase of temperature was also observed in the bulk of feed and distillate, respectively, by means of an IR-camera (Figures 9 shows the thermograph picture obtained during a DCMD experiment carried out at a temperature of the feed of $60^{\circ} \mathrm{C}$ ). In both cases, the difference of the temperature between the inlet and the outlet is of ca. $2^{\circ} \mathrm{C}$. Moreover, the picture evidenced the external part of the module at room temperature, whereas the central region in contact with the feed is at a temperature close to $60^{\circ} \mathrm{C}$. The membrane module exposed to this difference of temperature is subjected to heat transfer and as a consequence lateral regions of the feed are at lower temperature.

a)

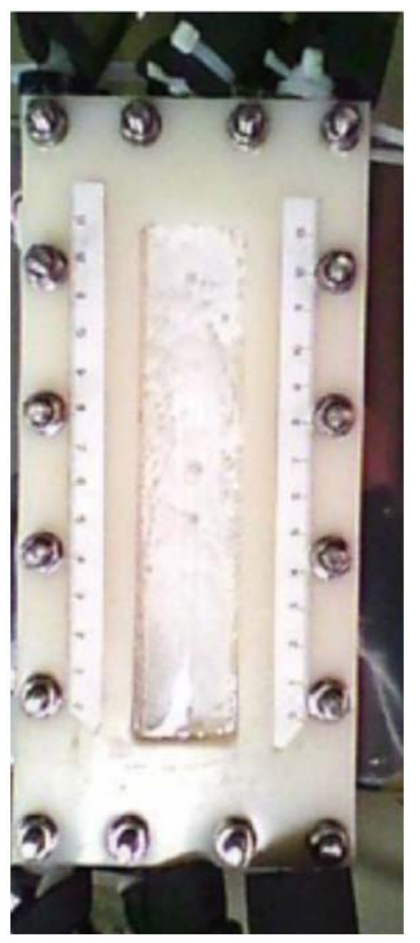

b)

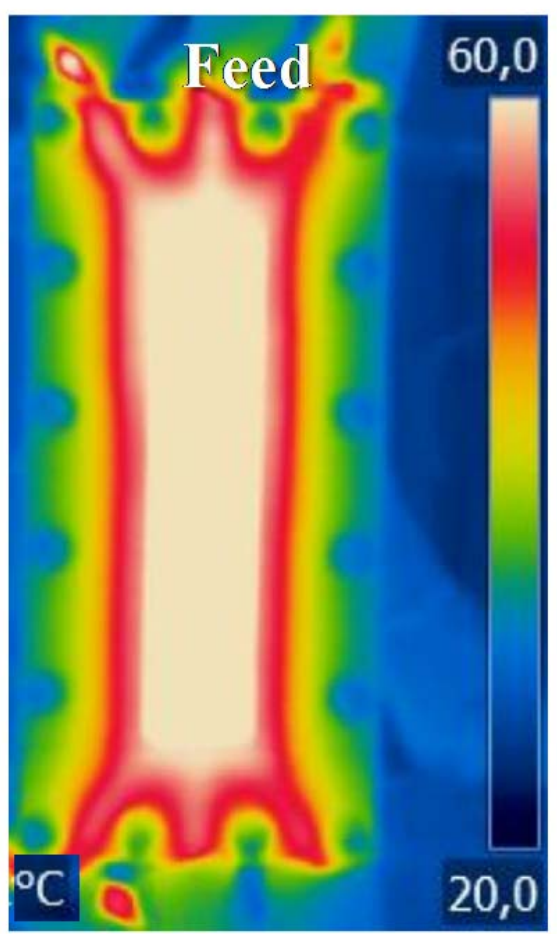

c)

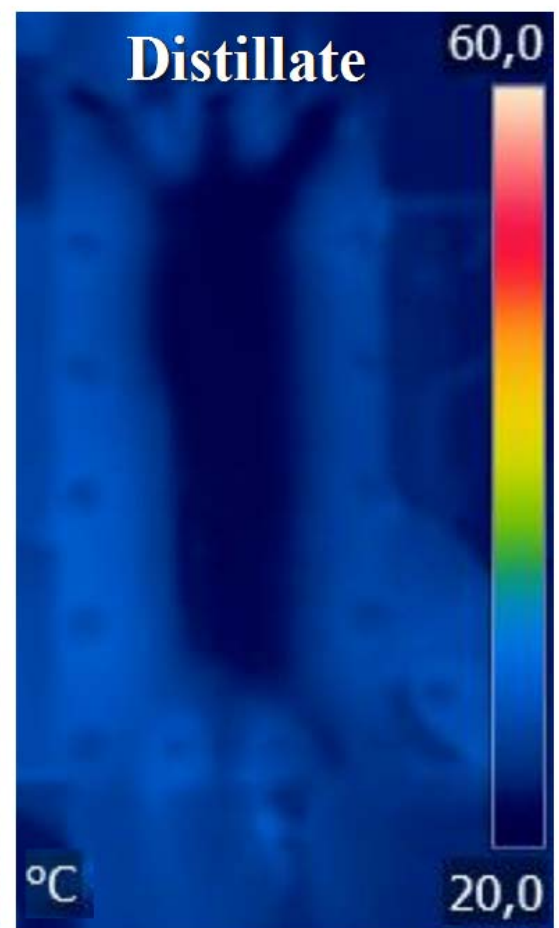

Figure 9: Picture of the membrane module (a); infrared pictures of the feed compartment (b) and the distillate compartment (c) at a feed inlet temperature of $60^{\circ} \mathrm{C}$. 
The combination of the two optical techniques: IR observation for the evaluation of the temperature of the bulk of the feed and distillate $\left(\mathrm{T}_{\mathrm{F}}\right.$ and $\left.\mathrm{T}_{\mathrm{D}}\right)$, and the emitted luminescence of the membrane doped with the molecular probes for the evaluation of the temperature on membrane surface $\left(\mathrm{T}_{\mathrm{F}, \mathrm{M}}\right.$ and $\left.\mathrm{TM}_{\mathrm{D}, \mathrm{M}}\right)$, provided the information needed to evaluate the thermal polarization. In fact, the temperature polarization coefficient (TPC) is defined as the ratio between the actual driving force (across the membrane) and the theoretical driving force (across the streams bulk) $[52,53]$ and is expressed mathematically as following:

$$
T P C=\frac{T_{F, M}-T_{D, M}}{T_{F}-T_{D}}(3)
$$

where is $T_{D}$ the temperature of the bulk distillate, $T_{D, M}$ is the membrane temperature at the distillate side, $\mathrm{T}_{\mathrm{F}}$ is the temperature of the bulk feed and $\mathrm{T}_{\mathrm{F}, \mathrm{M}}$ is the membrane temperature at the feed side .

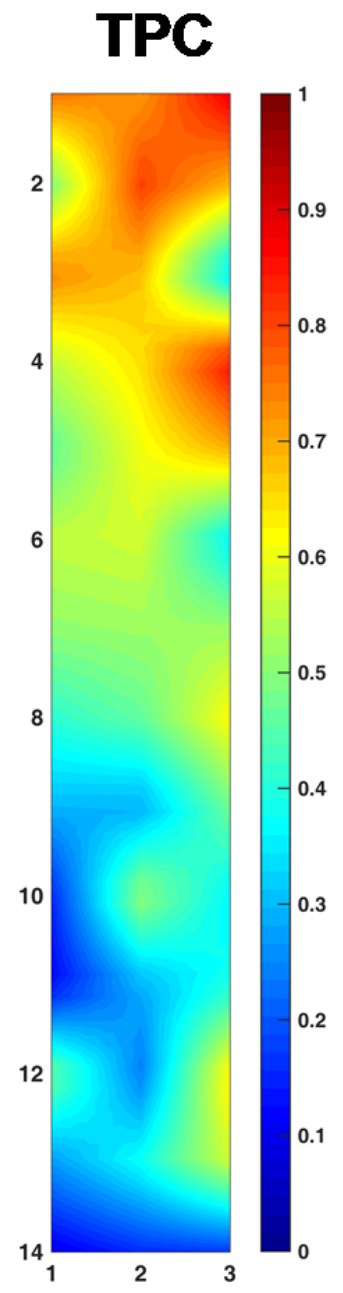

Figure 10: Maps of TPC at the feed temperature of $60^{\circ} \mathrm{C}$. 
The map of the TCP (Figure 10) calculated according to Eq.3 showed that the thermal polarization phenomena increased along the membrane module due to the heat employed for the vaporization and that one conducted through the membrane that dramatically reduced the $\mathrm{T}_{\mathrm{F}, \mathrm{M}}$ and increased the $\mathrm{T}_{\mathrm{D}, \mathrm{M}}[23]$.

\section{Conclusions}

A PVDF membrane prepared via electrospinning and loaded with a temperature sensitive luminescent probe for the non-invasive and in-situ monitoring of the thermal polarization in DCMD process was successfully produced. The homogeneity of the membrane made by a 3D network of nano-fibers was optimized indicating the key role of the concentration of the polymer and electrical conductivity given by the additives in the dope solution. The addition of salts, in particular $\mathrm{LiCl}$ and $\mathrm{Ru}(\text { phen })_{3}$, at optimal concentration of $0.83 \mathrm{wt} \%$ and $0.43 \mathrm{wt} \%$ respectively, in the polymeric solution lead to the preparation of a defect free homogeneous membrane almost free of defects. There is a trade off when the concentration of salts increases between the increase of viscosity that limits the spinnability and the minimization of beads in the fibers. This result has been confirmed by the promising results in terms of water flux in DCMD experiments. Furthermore, the doping with $\mathrm{Ru}(\mathrm{phen})_{3}$ confers to the PVDF membrane photochemical activity and, as expected, its emission intensity linearly decreases by increasing the temperature. These properties combined with the development of a devoted membrane module with a transparent window allowed the monitoring of the temperature of the membrane surface in-situ and in a non-invasive way.

Using an IR-Camera, it was possible to monitor the temperature of the bulk and the heat lost by the membrane module, too. The combination of the two optical techniques (IR camera and phosphorescence) led to the mapping of the difference of temperature between the bulk and membrane surface (the TPC), which increases along the membrane module.

According to these results, molecular probes could be considered an innovative and interesting tool for monitoring temperature on membrane surfaces on-line and in real-time, providing an important feedback in the development of high performance membranes and membrane modules and optimization of the operating conditions. In fact, the flow dynamics plays a key role in optimizing the DCMD performance and the maps of TPC can provide crucial information about the effect of the turbulence induced by the membrane module and feed velocity on the temperature polarization. 
Further studies will be focused on the effect of the operating conditions and membrane properties on the thermal polarization, wetting phenomena and the performance of DCMD process, in long-term runs.

\section{Acknowledgements}

Sergio Santoro would like to thank The Education, Audiovisual and Culture Executive Agency (EACEA) for the $\mathrm{PhD}$ grant under the Program "Erasmus Mundus Doctorate in Membrane Engineering" - EUDIME (http://www.eudime.unical.it). Artur Moro and Carla A. M. Portugal acknowledge the financial support of "Fundação para a Ciência e Tecnologia" (FCT-MCTES, Portugal) through the Post-Doc grants nr. SFRH / BPD / 69210 / 2010 and SFRH / BPD / 103619 / 2014. Ivan Moreno acknowledge the PhD grant to the Aragon Government, DGA, reference B008/12. The microscopy works have been conducted in the "Laboratorio de Microscopias Avanzadas" at "Instituto de Nanociencia de Aragon Universidad de Zaragoza" . Authors acknowledge the LMA-INA for offering access to their instruments and expertise. 


\section{References}

[1] Drioli, E, Criscuoli, A, and Curcio, E. Membrane contactors: fundamentals, applications and potentialities, in: Membrane Science and Technology Series. Elsevier, 2006.

[2] Criscuoli, A, Zhong, J, Figoli, A, Carnevale, M C, Huang, R R, and Drioli, E. Treatment of dye solutions by vacuum membrane distillation. Water Research, 42(2): 5031-5037, 2008.

[3] Alkhudhiri, A, Darwish, N, and Hilal, N. Membrane distillation: A comprehensive review. Desalination, 287: 2-18, 2012.

[4] García-Payo, M C, Essalhi, M, and Khayet, M. Effects of PVDF-HFP concentration on membrane distillation performance and structural morphology of hollow fiber membranes. Journal of Membrane Science, 347:209-219, 2010.

[5] Cipollina, A, Di Sparti, M G, Tamburini, A, and Micale, G. Development of a Membrane Distillation module for solar energy seawater desalination. Chemical Engineering Research and Design, 90:(12) 2101-2121, 2012.

[6] Alklaibi, A M, and Lior, L. Membrane-distillation desalination: Status and potential. Desalination,17(2), 111-131,2005 .

[7] Essalhi, M, and Khayet, M. Fundamentals of membrane distillation, in: Pervaporation,Vapour Permeation and Membrane Distillation. Elsevier, 2015.

[8] Phattaranawik, J, Jiraratananon, R, and Fane, A G. Effect of pore size distribution and air flux on mass transport in direct contact membrane distillation. J Journal of Membrane Science, 215, (1-2):75-85, 2003.

[9] Gryta, M. Influence of polypropylene membrane surface porosity on the performance of membrane distillation process. Journal of Membrane Science, 287(1): 67-78, 2007.

[10] Liu, F, Hashim, N A, Liu, Y, Abed, M R M, and Li, K. Progress in the production and modification of PVDF membranes. Journal of Membrane Science, 375(1-2):1-27, 2011.

[11] Tijing, L D, Choi, J, Lee, S, Kim, S, and Shon, H K. Recent progress of membrane distillation using electrospun nanofibrous membrane. Journal of Membrane Science, 453:435-462, 2014.

[12] Prince, J A, Rana, D, Singh, G, Matsuura, T, Jun Kai, T, and Shanmugasundaram, T S. Nanofiber based triple layer hydro-philic/-phobic membrane-a solution for pore wetting in membrane distillation. Sci. Rep., 4: 6949-6955, 2014. 
[13] Khayet, M, and García-Payo, M C. Nanostructured Flat Membranes for Direct Contact Membrane Distillation. PCT/ES2011/000091, WO/2011/117443, 2011.

[14] Feng, C, Khulbe, K C, Matsuura, T, Gopal, R, Kaur, S, Ramakrishna, S, and Khayet, M. Production of drinking water from saline water by air-gap membrane distillation using polyvinylidene fluoride nanofiber membrane. Journal of Membrane Science, 311(1-2):16, 2008.

[15] Feng, C, Khulbe, K C, and Tabe, S. Volatile organic compound removal by membrane gas stripping using electro-spun nanofiber membrane. Desalination, 287:98$102,2012$.

[16] Liao, Y, Wang, R, , M, Qiu, C, and Fane, A G. Fabrication of polyvinylidene fluoride (PVDF) nanofiber membranes by electro-spinning for direct contact membrane distillation. Journal of Membrane Science, 425-426:30-39, 2013.

[17] Hitsov, I, Maere, T, De Sitter, K, Dotremont, C, and Nopens, I. Modelling approaches in membrane distillation: A critical review. Separation and Purification Technology ,142:48-64, 2015.

[18] Martinez-Diez, L, and Vázquez-González, M I. A method to evaluate coefficients affecting flux in membrane distillation. Journal of Membrane Science, 173(2):225-234, 2000.

[19] Martínez-Díez, L, and Rodríguez-Maroto, J M. Characterization of membrane distillation modules and analysis of mass flux enhancement by channel spacers. Journal of Membrane Science, 274(1-2): 123-137, 2006

[20] Cheng, L, Wu, P, and Chen, J. Modeling and optimization of hollow fiber DCMD module for desalination. Journal of Membrane Science, 318(1-2):154-166, 2008.

[21] Chen, T CHo, C D, and Yeh, H M. Theoretical modeling and experimental analysis of direct membrane distillation. Journal of Membrane Science, 330(2): 279-287, 2009.

[22] Ding, Z, Ma, R, and Fane, A G. A new model for mass transfer in direct contact membrane distillation. Desalination, 151(3): 217-227, 2002.

[23] Ali, A, Macedonio, F, Drioli, E, Aljlil, S, and Alharbi, A O. Experimental and theoretical evaluation of temperature polarization phenomenon in direct contact membrane distillation. Chemical Engineering Research and Design, 91(10):1966-1977, 2013.

[24] Tamburini, A, Pitò, P, Cipollina, A, Micale, G, and Ciofalo, M. A Thermochromic Liquid Crystals Image Analysis technique to investigate temperature polarization in 
spacer-filled channels for Membrane Distillation. Journal of Membrane Science, 447:260-273, 2013.

[25] Yang, J M, Yang, H, and Lin, L. Quantum dot nano thermometers reveal heterogeneous local thermogenesis in living cells. ACS Nano, 5(6): 5067-5071, 2011.

[26] Filevich, O, and Etchenique, R. ID and 2D temperature imaging with a fluorescent ruthenium complex. Analytical Chemistry, 78(21): 7499-7503, 2006.

[27] Santoro, S, Moro, A J, Portugal, C M, Crespo, J G, Coelhoso, I M, Lima, J C, Development of Oxygen and Temperature Sensitive Membranes Using Molecular Probes as Ratiometric Sensor. Journal of Membrane Science, 514:467-475, 2016.

[28] Santoro, S, Moro, A J, Portugal, C M, Crespo, J G, Lima, J C, Coelhoso, I M, Monitoring oxygen permeation through polymeric packaging films using a ratiometric luminescent sensor, Journal of Food Engineering 189: 37-44, 2016.

[29] Santoro, S, Sebastian, V, Moro, A J, Portugal, C M, Crespo, J C, Lima, J C, Coelhoso, I M, Mallada, R, Development of Fluorescent Nano-ther mometers for temperature monitoring on membrane surfaces, Journal of Colloids and Interface 486:144-152, 2017.

[30] Demas, J N, and DeGraff, B A. Applications of Luminescent Transition Platinum Group Metal Complexes to Sensor Technology and Molecular Probes. Coor. Chem Rev., 211: 317-351, 2001.

[31] Liebsch, G, Klimant, I, and Wolfbeis, O S. Luminescence Lifetime Temperature Sensing Based on Sol-Gels and Poly(acrylonitrile)s Dyed with Ruthenium Metal-Ligand Complexes. Adv. Mater., 11(15): 1296-1299, 1999.

[32] Ahmed, F E, Lalia, B S, Hashaikeh, R. A review on electrospinning for membrane fabrication: Challenges and applications. Desalination, 356:15-30, 2015.

[33] Homaeigohar, S, Koll, J, Lilleodden, E T, Elbahri, M. The solvent induced interfiber adhesion and its influence on the mechanical and filtration properties of polyethersulfone electrospun nanofibrous microfiltration membranes. Sep. Purif. Technol. 98: 456-463, 2012.

[34] Figoli, A, Simone, S, Criscuoli, A, AL-Jlil, S A, Al Shabouna, F S, Al-Romaih, H S, Di Nicolò, E, Al-Harbi, O A, and Drioli, E. Hollow fibers for seawater desalination from blends of PVDF with different molecular weights: Morphology, properties and VMD performance. Polymer, 55: 1296-1306, 2014.

[35] Chan, L S, Cheung, W H, and McKay, G. Adsorption of acid dyes by bamboo derived activated carbon. Desalination, 218(1-3): 304-312, 2008.

[36] Liao, Y, Wang, R, Tian, M, Qiu, C, and Fane, A G. Fabrication of polyvinylidene fluoride (PVDF) nanofiber membranes by electro-spinning for direct contact membrane distillation. Journal of Membrane Science, 425-426:30-39, 2013. 
[37] Deitzel, J M, Kleinmeyer, J, Harris, D, and Beck Tan, N C. The effect of processing variables on the morphology of electrospun nanofibers and textiles. Polymer, 42(1):261272, 2001.

[38] Zong, X, Kim, K, Fang, D, Ran, S, Hsiao, B S, and Chu, S. Structure and process, relationship of electrospun bioabsorbable nanofiber membranes. Polymer, 43(16):4403$4412,2002$.

[39] Wenzel, R N. Ind. Eng. Chem., 28(8): 988-994, 1936.

[40] Solef® \& Hylar ${ }^{\circledR}$ PVDF Polyvinylidene fluoride Design and Processing Guide.

[41] Lei, Z, Chen, B, and Ding, Z. Membrane distillation, in: Special Distillation Processes. Elsevier Science, 2005.

[42] Wu, H Y, Wang, H G, and Field, R T W. Direct contact membrane distillation: An experimental and analytical investigation of the effect of membrane thickness upon transmembrane flux. Journal of Membrane Science, 470: 257-265, 2014.

[43] Laganà, F, Barbieri, G, and Drioli, E. Direct contact membrane distillation: modelling and concentration experiments. Journal of Membrane Science, 16(1):1-11, 2001.

[44] Prince, J A, Rana, D, Singh, G, Matsuura, T, Jun Kai, T, and Shanmugasundaram, T S. Effect of hydrophobic surface modifying macromolecules on differently produced PVDF membranes for direct contact membrane distillation. Chem. Eng. J., 242:387-396, 2014.

[45] Prince, J A, Singh, G, Rana, D, Matsuura, T, Anbharasi, V, and Shanmugasundaram, T S. Preparation and characterization of highly hydrophobic poly(vinylidene fluoride) clay nanocomposite nanofiber membranes PVDF-clay NNMs) for desalination using direct contact membrane distillation. Journal of Membrane Science, 397-398: 80-86, 2012.

[46] Essalhi, M, and Khayet, M. Self-sustained webs of polyvinylidene fluoride electrospun nanofibers at different electrospinning times: 1 . Desalination by direct contact membrane distillation. Journal of Membrane Science, 433:167-179, 2013.

[47] Liao, Y, Wang, R, and Fane, A G. Fabrication of bioinspired composite nanofiber membranes with robust superhydrophobicity for direct contact membrane distillation. Environ. Sci. Technol. 48(11) (2014) 6335-6341.

[48] Liao, Y, Loh, C-H, Wang, R, and Fane, A G. Electrospun superhydrophobic membranes with unique structures for membrane distillation. ACS Appl. Mater.Interfaces, 6(18):16035-16048, 2014. 
[49] Tijing, L D, Woo, Y C, Shim, W-G, He, T, Choi, J-S, Kim, S-H, and Shon, H K. Superhydrophobic nanofiber membrane containing carbon nanotubes for highperformance direct contact membrane distillation. Journal of Membrane Science, 502:158-170, 2016.

[50] Sauer, M, Hofkens, J, and Enderlein, J. Basic Principles of Fluorescence Spectroscopy, in: Handbook of Fluorescence Spectroscopy and Imaging: From Single Molecules to Ensembles. Wiley, 2011.

[51] McRae, E G. Theory of solvent effects on molecular electronic spectra. Frequency shifts. J. Phys. Chem. 61: 562-572, 1957.

[52] Schofield, R.W., Fane, A.G., Fell, C.J.D. Heat and mass transfer in membrane distillation. Journal of Membrane Science, 33: 299-313, 1987.

[53] Qtaishata, M., Matsuuraa , T., Kruczeka, B., Khayet, M. Heat and mass transfer analysis in direct contact membrane distillation. Desalination, 219: 272-292, 2008. 


\section{Abbreviation}

CA: Contact Angle

DCMD: Direct Contact Membrane Distillation

DMF: Dimethylformamide

$d_{p}$ : pore size

ENM: electrospun nanofibrous membrane

LEP: Liquid Entry Pressure

LiCl: Litium Clhoride

MD: Membrane Distillation

P: Porosity

$\mathrm{Ru}(\text { phen })_{3}$ : Tris(phenantroline)ruthenium(II) chloride

PVDF: Poly(vinylidene fluoride)

SEM: Scanning Electron Microscopy

$\mathrm{T}_{\mathrm{D}}$ : Temperature of the bulk distillate

$\mathrm{T}_{\mathrm{D}, \mathrm{M}}$ : Membrane temperature at the distillate side

$\mathrm{T}_{\mathrm{F}}$ : Temperature of the bulk feed

$\mathrm{T}_{\mathrm{F}, \mathrm{M}}$ : Membrane temperature at the feed side

$\mathrm{w}_{\mathrm{d}}$ : weight of the dry membrane

$\mathrm{w}_{\mathrm{h}}$ : weight of the wet membrane;

$\rho_{\mathrm{w}}$ : kerosene density

$\rho_{\text {PVDF }}:$ PVDF density

$\tau:$ surface tension

$\theta$ :contact angle 
